Иванова А.В., Костина Н.В., Лысенко Т.М., Козловская О.В.

15. Раков Н.С., Саксонов С.В., Сенатор С.А. Флора озера Песчаное (Ульяновское Заволжье) // Известия Самарского научного центра Российской академии наук. 2013. Т. 15, № 3. С. 88-96.

16. Раков Н.С. Флора озера Яик в окрестностях поселка Чердаклы (Ульяновское Заволжье) // Самарская Лука: проблемы региональной и глобальной экологии. 2015. Т. 24, № 3. С. 171-180.

17. Сенатор С.А., Саксонов С.В., Раков Н.С., Васюков В.М., Иванова А.В., Сидякина Л.В. Сосудистые растения Тольятти и окрестностей (Самарская область) // Фиторазнообразие Восточной Европы. 2015. T. IX. № 1. C. 32-101.
18. Савенко О.В., Сенатор С.А. Выявление степени антропогенной трансформации флоры на примере Мелекесско-Ставропольского ландшафтного района // Аграрная Россия. 2009. № S1. С. 56-57.

19. Preston F.W. The canonical distribution of commonness and rarity // Ecologoy. 1962. № 3. P. 410-432.

20. Иванова А.В., Костина Н.В. Исследование флористической неоднородности Сокского бассейна (Самарская область, Заволжье) // Вестник Удмуртского университета. Серия Биология. Науки о Земле. 2013. № 6-3. C. 29-34.

Статья публикуется при поддержкке гранта РФФИ № 16_04_00747_a.

\title{
THE FLORA PECULIARITIES OF THE MELEKESS-STAVROPOL PHYSIOGRAPHIC REGION
} (C) 2017

Ivanova Anastasiya Victorovna, candidate of biological sciences, researcher of Phytodiversity Problems Laboratory

Kostina Natalia Victorovna, candidate of biological sciences, senior researcher of Modeling and Management of Ecosystems Laboratory

Lysenko Tatyana Mikhajlovna, doctor of biological sciences, leading researcher of Phytodiversity Problems Laboratory Institute of Ecology of the Volga River Basin of Russian Academy of Sciences (Togliatti, Samara Region, Russian Federation)

Kozlovskaya Olga Victorovna, candidate of biological sciences, associate professor of Chemical Technology and Industrial Ecology Department Samara State Technical University (Samara, Samara area, Russian Federation)

Abstract. We publish the results of a three-stage study of the floristic heterogeneity of the Melekess-Stavropol physiographic region located on the territory of the Samara and Ulyanovsk Regions. The area belongs to the foreststeppe zone of the Trans Volga Lowland and occupies the area of 7,7 thousand $\mathrm{km}^{2}$. Based on the analysis of family spectra, originality of the flora of the region we show the comparison of Soksky and Irgiz physiographic regions of the Samara Trans Volga. At the first stage of the research we consider the internal heterogeneity of the region, changes in the species composition of the flora along a two-sided latitudinal gradient. For this, the course of the curve, reflecting the accumulation of the number of species with an increase in area, has been studied. The accumulation curves of the number of species aligned in both directions showed three stages of an increase in the number of species, indicating the species heterogeneity of the area. The study of the position of the leading families, depending on the size and geographical position of the floristic sample, shows the heterogeneity of the studied MelekessStavropol region by the flora type, which is determined by the third term of the first triple of the family spectrum.

At the second stage, four floral groups (floristic samples) are analyzed, which are geographically isolated at the first step. A comparison is made of the isolated groupings at the head of the family spectra using the fraction of the family in the flora and the number of species in the family. The third stage includes a comparison of the selected floral groups of the Melekess-Stavropol physio-geographical region according to the Preston index. Taking into account the existing numerical threshold of 0,27 , above which the samples should be considered as different floras, it is possible to speak of the presence of four different floras on the territory of the studied area.

Keywords: Melekess-Stavropol physiographic region; Trans Volga Lowland; Samara Region; Ulyanovsk Region; head part of family spectrum; FD database SUR; floristic descriptions; floristic groupings; type of flora; floristic heterogeneity; share of family; Preston difference indicator.

УДК 595.7

Статья поступила в редакцию 17.09.2017

\section{НЕКОТОРЫЕ РЕЗУЛЬТАТЫ ИЗУЧЕНИЯ ЭНТОМОФАУНЫ СОЦВЕТИЙ ЛОПУХОВ (ASTЕRАСЕАЕ: ARСТIUМ) В ЕЛАБУЖСКОМ РАЙОНЕ РЕСПУБЛИКИ ТАТАРСТАН}

(C) 2017

Леонтьева Ирина Александровна, старший преподаватель кафедры биологии и химии

Елабужский институт (филиал) Казанского (Приволжского) федерального университета (2. Елабуга, Республика Татарстан, Российская Федераичя)

Аннотащия. На территории Елабужского района Республики Татарстан (РТ) лопухи (Asteraceae, Arctium) встречаются повсеместно и являются одними из самых распространенных видов среди сложноцветных растений. Являются они в основном рудеральными сорняками, произрастающими обычно по мусорным местам (заброшенные огороды, пустыри, овраги, обочины дорог, берега рек, свалки, у стен домов и заборов и др.). Также некоторые представители этого рода встречаются в пойменных лесах, в разреженных лиственных леcax, на вырубках, опушках. 
В работе представлены некоторые результаты исследования видового состава и структуры популяции насекомых-фитофагов, развивающихся в соцветиях четырех видов лопухов (Arctium tomentozum, Arctium minus, Arctium lappa, Arctium nemorosum) на территории Елабужского района Республики Татарстан. Всего было обследовано семь опытных участков, общая площадь которых составляла в среднем 1,0 га. Основные исследования по выявлению энтомофауны соцветий лопухов проводились во время весенне-летнего периода 2015-2017 гг. в момент активного цветения растений. Было обнаружено три вида мух-пестрокрылок (Diptera: Tephritidae), один вид мухи-галлицы (Cecidomyiidae spp.), один вид жука-долгоносика (Curculionidae) и один вид моли выемчатокрылой (Gelechiidae).

Ключевые слова: насекомые-фитофаги; разнообразие; соцветия; кормовое растение; Arctium tomentozum; Arctium minus; Arctium lappa; Arctium nemorosum; пищевая специализация; фитофагия; Двукрылые; Жесткокрылые; Чешуекрылые; город Елабуга; Елабужский район; Республика Татарстан.

\section{Введение}

На территории Елабужского района РТ произрастает четыре вида лопухов (Arctium tomentozum, A. minus, A. lappa, A. neтоrosum) и несколько их гибридных форм. Самым распространенным и повсеместно встречаемым является лопух паутинистый (A. tomentozum), образующий большие заросли, преимущественно в рудеральных местах. На тех же местах, что и A. tomentozum, но реже, встречаются лопухи малый (A. minus) и большой (A. lappa). Однако они в большей степени предпочитают опушечные и лесные биотопы. Лопух лесной (A. nemorosum) отмечается крайне редко на зарастающих дорогах, вырубках и лесных полянах.

С зелеными растениями, в том числе и с лопухами, связано большое количество насекомых, которые, с одной стороны, играют большую роль в опылении культурных и дикорастущих растений, участвуют в почвообразовании, с другой - тесно связаны с растениями в процессе питания или размножения. $\mathrm{C}$ растениями связаны насекомые разных трофических групп (хищники, паразиты, опылители), однако преобладающее значение имеют насекомые-фитофаги (Phytophaga).

Фитофаги являются важным компонентом любой природной экосистемы. Одни виды фитофагов способны питаться отдельными частями растения (листьями, стеблями, цветками и др.), другие способны развиваться внутри растения, а именно в соцветиях, стеблях, корнях или плодах. Таким образом, между растениями и насекомыми создаются различного рода трофические, топические и другие виды взаимоотношений. В результате этого у растений в процессе эволюции сформировались различные защитные приспособления от действия фитофагов. В ходе эволюции возникли две большие группы насекомыхфитофагов: насекомые, обитающие внутри тканей растения (эндофитобионты), и на растениях (эктофитобионты). У первой группы ввиду специфической среды обитания выработались очень тесные взаимоотношения с их кормовыми растениями, что обусловливает высокую степень пищевой специализации [1, с. 3-4].

Фитофагия, как способ питания, развивается среди большого количества насекомых. Растительноядных много, например, среди жесткокрылых (листоеды (Chrysomelidae), майские хрущи (Scarabaeidae), златки (Buprestidae), щелкуны (Elateridae), трубковерты (Attelabidae), долгоносики (Curculionidae)), перепончатокрылых (пилильщики (Tenthredinidae, Cephidae и др.), двукрылых (мухи-пестрокрылки (Терhritidae), галлицы (Cecidomyiidae), чешуекрылых (голубянки (Lycaenidae), шелкопряды (Bombycidae)) и др. Представители некоторых отрядов, например чешуекрылых, являются растительноядными только на стадии личинок.

Насекомые-фитофаги специализируются, как правило, по питанию либо на растениях определенных семейств, либо на отдельных частях растения [2-8].

В настоящее время недостаточно изучен видовой состав насекомых-фитофагов соцветий сложноцветных растений в условиях городской среды. Важной особенностью большинства групп фитофагов является их узкая специализация по отношению к питанию или развитию в определенных органах растений. Поэтому наряду с выявлением видового состава, изучением условий распространения и ландшафтной приуроченности важной задачей при эколого-фаунистическом изучении насекомых-фитофагов является выявление регионального спектра кормовых растений и анализ трофических связей той или иной растительноядной группы.

Целью наших исследований явилось изучение энтомофауны соцветий лопухов, как одних из самых распространенных видов в условиях Елабужского района РT.

\section{Материал и методика исследований}

Материал для данного исследования собирался на протяжении двух лет (2015-2017 гг.) в разных биотопах Елабужского района РТ, на которых встречались обширные заросли лопухов (заброшенные пустыри, обочины дорог, заброшенные огороды, овраги, балки и жилые зоны г. Елабуги). Всего было обследовано 7 участков, общей площадью в 1,0 га. На каждом исследуемом участке изучался видовой состав травянистой, древесной и кустарниковой растительности [9]. Для определения плотности лопухов в местах их произрастания закладывались учетные площадки размером 5 м². На них подчитывалось общее количество растений и среднее количество соцветий на одно растение. Кроме этого определялась средняя плотность лопухов на $1 \mathrm{~m}^{2}$. Лопух лесной нами на исследуемых участках не обнаружен.

Объектом исследования являлись сборы насекомых-фитофагов, обитающих в соцветиях лопухов на разных стадиях их развития в условиях Елабужского района РТ.

Энтомологический материал был получен путем выведения насекомых из соцветий кормовых растений. Для этого соцветия лопухов исследуемых видов собирались во всех исследуемых биотопах в июлеавгусте. Собирались в основном цветущие и отцветшие соцветия, т.к. в это время и происходило откладывание яиц насекомыми. После этого соцветия помещались в стеклянные банки для выведения имаго. Каждая партия соцветий в банках сохранялась в ла- 
боратории достаточно долгое время, в течение нескольких месяцев. Банки периодически просматривались, встряхивались, для того чтобы соцветия в них не заплесневели; при чрезмерной сухости соцветия, напротив, опрыскивались водой. Через две недели после закладывания соцветий начали появляться имаго насекомых, которые изымались из банок.

Часть соцветий использовалась для анализа характера заселения их фитофагами. Такие соцветия осматривались, вскрывались и выбирались только те, которые были заражены личинками насекомых. Подсчитывалось общее количество семян в соцветии и количество поврежденных семян.

Кроме основного сбора, энтомологический материал собирался с помощью энтомологического сачка. В данном случае собирались имаго насекомых непосредственно с кормовых растений в исследуемых участках.

\section{Результаты и обсуждение}

Сравнительный анализ группировок насекомых фитофагов на опытных участках проводился с использованием общепринятых методов математической статистики.

В ходе исследования нами из соцветий лопухов было собрано и выведено 6 видов насекомых, относящихся к трем отрядам и четырем семействам:

Отряд Diptera

Подотряд Brachycera

Семейство Tephritidae

Род Terellia Robineau-Desvoidy, 1830

T. (Cerajocera) tussilaginis (Fabricius, 1775) - Ceмяед лопуховый

Род Tephritis Latreille, 1804

T. bardanae (Schrank, 1809) - Пестрокрылка лопуховая или репейная

Род Chaetostomella Hendel, 1927

C. cylindrica (Loew, 1846) - Пестрокрылка многоядная

Подотряд Nematocera

Семейство Cecidomyiidae spp. - Галлицы

Отряд Coleoptera

Семейство Curculionidae

Род Larinus Dejean, 1821

L. (Phyllonomeus) sturnus (Schaller, 1783) - Долгоносик - ларинус стурнус

Отряд Lepidoptera

Семейство Gelechiidae

Род Metzneria Zeller, 1839

M. lappella (Linnaeus, 1758) - Моль репейная выемчатокрылая.

Популяции лопухов, произрастающие по сорным местам, интенсивно заселяются фитофагами во всех исследуемых стациях (табл. 1).

Однако степень заселения соцветий лопухов насекомыми достаточно низкая (от $32,6 \%$ до 52,2\%), несмотря на то что, с одной стороны, плотность соцветий на одно растение достаточно высокая, с другой стороны, обнаруженные нами виды широко представлены в регионе исследования.

После изучения фауны насекомых-фитофагов в соцветиях лопухов исследуемой территории были получены следующие результаты. В соцветиях лопуха паутинистого (A.tomentosum) были представлены все обнаруженные нами виды: личинки мух-пестро- крылок (T.tussilaginis, T. bardanae, C. cylindrica) и жука-долгоносика L. sturnus, гусеницы M. lappella, галлицы (Cecidomyiidae spp.). Однако степень заселения соцветий данного вида кормового растения фитофагами незначительна. Средний процент заселения соцветий лопуха паутинистого фитофагами на исследуемых участках составил всего 40,2\% (рис. 1).

Таблица 1 - Характер заселения соцветий лопухов фитофагами в исследуемых стациях

\begin{tabular}{|c|c|c|c|c|c|}
\hline \multirow{2}{*}{$\begin{array}{l}\text { № } \\
\Pi / \Pi\end{array}$} & \multirow{2}{*}{ Место сбора } & \multirow{2}{*}{\begin{tabular}{|c|} 
Кол-во \\
прове- \\
ренных \\
соцветий
\end{tabular}} & \multicolumn{2}{|c|}{$\begin{array}{c}\text { Из них } \\
\text { заражено }\end{array}$} & \multirow{2}{*}{$\begin{array}{l}\text { Чистые } \\
\text { соцве- } \\
\text { тия (\%) }\end{array}$} \\
\hline & & & $\mathrm{N}$ & $\%$ & \\
\hline 1 & $\begin{array}{l}\text { Елабуга. } \\
\text { Пустырь }\end{array}$ & 420 & 218 & 51,9 & $\begin{array}{r}202 \\
(48,1)\end{array}$ \\
\hline 2 & \begin{tabular}{|l} 
Елабуга. \\
Обочина дороги
\end{tabular} & 182 & 75 & 41,2 & $\begin{array}{r}107 \\
(58,8)\end{array}$ \\
\hline 3 & \begin{tabular}{|l} 
Елабуга. Дубра- \\
ва. Опушка
\end{tabular} & 460 & 152 & 33,0 & $\begin{array}{r}308 \\
(67,0)\end{array}$ \\
\hline 4 & $\begin{array}{l}\text { Елабужский рай- } \\
\text { он. Д. Хлыстово. } \\
\text { Пустырь }\end{array}$ & 385 & 149 & 38,7 & $\begin{array}{r}236 \\
(61,3)\end{array}$ \\
\hline 5 & $\begin{array}{l}\text { Елабуга. } \\
\text { Пастбище }\end{array}$ & 343 & 112 & 32,6 & $\begin{array}{r}231 \\
(67,4) \\
\end{array}$ \\
\hline 6 & $\begin{array}{l}\text { Елабужский рай- } \\
\text { он. С/Т «Весна». } \\
\text { Заброшенные } \\
\text { огороды }\end{array}$ & 368 & 192 & 52,2 & $\begin{array}{r}176 \\
(47,8)\end{array}$ \\
\hline 7 & $\begin{array}{l}\text { Елабуга. Забро- } \\
\text { шенные огороды }\end{array}$ & 264 & 116 & 43,9 & $\begin{array}{r}148 \\
(56,1) \\
\end{array}$ \\
\hline & Всего: & 2422 & 1014 & 41,9 & $\begin{array}{r}1408 \\
(58,1)\end{array}$ \\
\hline
\end{tabular}

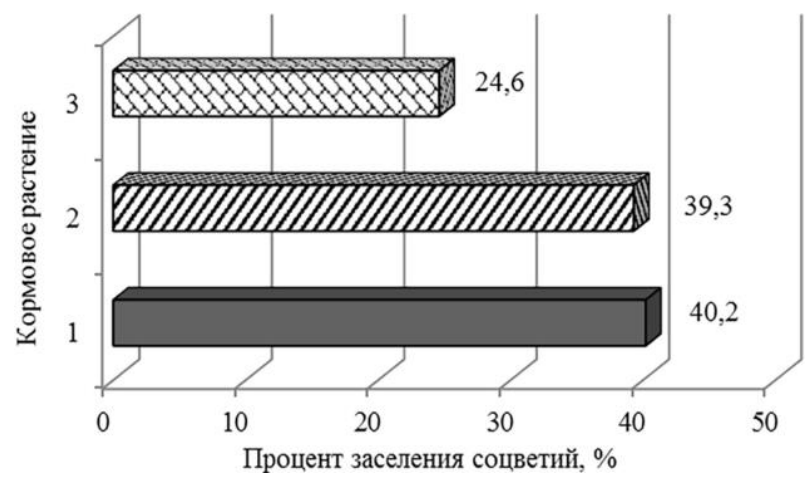

Рисунок 1 - Процент заселения соцветий лопухов насекомыми-фитофагами в исследуемых стациях (1-A. tomentosum, 2-A. lappa, 3-A. minus)

В соцветиях лопуха большого (A. lappa), обнаруженного на шести исследуемых участках, выявлены личинки мух-пестрокрылок, галлицы и личинки L. sturnus. Репейная выемчатокрылая моль (M. lappella) в соцветиях данного вида нами не обнаружена, хотя по литературным данным известно, что ее личинки развиваются в соцветиях всех видов лопухов. Средний процент заселения соцветий A. lappa насекомыми-фитофагами примерно такой же, как и лопуха паутинистого (39,3\%).

Лопух малый (A. minus) обнаружен нами только на трех исследуемых участках (третьем, четвертом и пятом), причем плотность его была гораздо ниже, чем других видов лопухов. Энтомофауна соцветий A. minus представлена четырьмя видами: T. bardanae, 
Леонтьева И.А.

Некоторые результаты изучения энтомофауны соцветий лопухов..

03.02.00 - общая биология

T. tussilaginis и L. sturnus, а также галлицами. Средний процент заселения соцветий A. тіпиs фитофагами низкий и составил всего $24,6 \%$.

Таким образом, видовое разнообразие насекомых-фитофагов в соцветиях лопухов в районе исследования практически одинаково. Однако степень заселения их соцветий теми или иными видами фитофагов различна. В тех местах, где совместно произрастают разные виды лопухов, фитофаги заселяют преимущественно соцветия лопуха паутинистого.

Среди представителей двукрылых насекомых (Diptera) доминантными являлись два вида тефритид (T. bardanae и T.tussilaginis). Основным кормовым растением T. bardanae является лопух паутинистый. Частота встречаемости данного вида в соцветиях лопуха паутинистого составила $71,2 \%$ от общего количества обнаруженных видов тефритид. Кроме этого, данный вид нами обнаружен в соцветиях лопухов большого и малого, однако частота встречаемости колебалась в широких пределах от 43,6 до $72,2 \%$ (рис. 2). Другим обычных видов мух-пестрокрылок на исследуемой территории являлся семяед лопуховый (T. tussilaginis). Долевое участие данного вида в энтомофауне лопухов составляет: на лопухе паутинистом $-26,7 \%$, лопухе большом - 50,9\%, лопухе малом $-27,8 \%$.

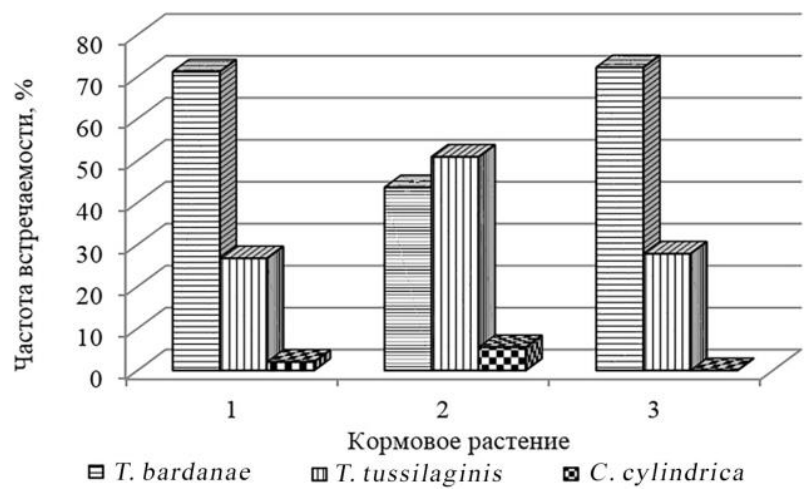

Рисунок 2 - Соотношение частот встречаемости мух-пестрокрылок, пойманных с помощью сачка на исследуемых участках.

1 - A. tomentosum; 2-A. lappa; 3-A. minus

Реже всего на соцветиях лопухов встречалась пестрокрылка многоядная (C. cylindrica). Этот вид обнаружен нами только на некоторых исследуемых участках, преимущественно за пределами городской черты. Частота встречаемости данного вида на исследуемых участках очень низкая и составляет всего $2,0-5,5 \%$.

Степень заселения соцветий лопухов разными видами пестрокрылок на исследуемых участках также различна. Наиболее интенсивно заселяются соцветия лопухов двумя видами: T. bardanae и T. tussilaginis (от 11,1 до $34,9 \%$ для 1-го вида и от 9,0 до $25,0 \%$ для 2-го вида), тогда как степень заселения соцветий C. cylindrica составляет всего от 1,9 до $5,1 \%$.

Кроме мух-пестрокрылок, в соцветиях лопухов обнаружены мухи-галлицы (Cecidomyiidae), личинки L. sturnus и M. lappella. Долевое участие этих видов на всех исследуемых участках составило от $57,1 \%$ до $71,4 \%$.

При изучении особенности распространения мухпестрокрылок как основного компонента энтомофауны лопухов выяснилось, что T. bardanae является строгим олигофагом и откладывает яйца только в бутоны лопухов примерно в конце июня - в начале июля. Она является типичным семяедом, ее личинки повреждают только развивающиеся семена в распускающихся головках лопуха [10]. Одна личинка способна повредить от 1 до 4 семян в соцветии в зависимости от общего их количества. Здесь же внутри соцветия личинки окукливаются; куколки черного цвета. В одном соцветии, как правило, насчитывается 3-8 личинок.

Лопуховый семяед (T. tussilaginis) также является типичным олигофагом и семяедом. Но в отличие от пестрокрылки лопуховой, предпочитает соцветия уже отцветающие или отцветшие, т.к. для развития ее личинок требуются зрелые семена большего размера. Соцветия с недоразвитыми семенами данный вид практически не заселяет. В соцветиях лопухов вместе с личинками T. tussilaginis одновременно были обнаружены личинки L. sturnus. Можно предположить, что личинки долгоносика разрушают семена кормового растения, тем самым способствуя гибели T. tussilaginis.

Пестрокрылка многоядная (C. cylindrica) является типичным полифагом, т.к. кроме соцветий лопухов предпочитает заселять соцветия василька шероховатого и бодяка разнолистного [11]. По способу питания является минером соцветий и цветоложа, проделывая в них многочисленные ходы.

Личинки долгоносика L. sturnus были обнаружены в соцветиях трех видов лопухов, однако предпочтение было отдано только двум видам - лопуху паутинистому и большому. Независимо от видовой принадлежности доля заселения соцветий лопухов долгоносиком в исследуемых биотопах незначительна и составляет всего от 6,1 до $25,1 \%$.

L. sturnus обнаружен нами на всех исследуемых участках, однако, как показали исследования, предпочтение отдает не городским биотопам, а более остепненным природным участкам, каковыми являются пустыри, замусоренные опушки лесов, заброшенные огороды, пастбища. Имаго появляется на соцветиях примерно в конце июня - начале июля. Этология данного вида широко изучена С.В. Воловником [8]. Самка долгоносика откладывает яйца в молодые, еще не раскрывшиеся соцветия лопухов через выгрызаемое отверстие в нижней части соцветия. В одном соцветии могут развиваться сразу несколько личинок. Они питаются цветоложем и незрелыми семенами лопухов. В отличие от личинок пестрокрылок, личинка последнего возраста делает вокруг себя камеру из остатков семян, в которой впоследствии зимует.

В отдельных исследуемых биотопах в соцветиях лопухов паутинистого и большого нами были обнаружены личинки репейной выемчатокрылой моли (M. lappella). Личинки ее достаточно крупные, развиваясь в соцветиях, объедают цветоложе и повреждают семена. В одном соцветии, как правило, развивается одна личинка. Одновременно с личинками моли в соцветиях лопухов находились и личинки мух. Степень заселения соцветий лопухов репейной выемчатокрылой молью незначительна и не превышает $5,0 \%$.

Значительных различий в видовом составе фитофагов в соцветиях лопухов паутинистого, большого и малого в ходе исследования с помощью индекса Чекановского нами не выявлено. 
Таким образом, в целом энтомофауна соцветий лопухов в условиях Елабужского района РТ достаточно однообразна, однако, как показали исследования, интенсивность заселения соцветий лопухов разных видов насекомыми-фитофагами различна. При совместном произрастании лопухов разных видов на одном участке фитофаги предпочитали заселять соцветия лопуха паутинистого.

\section{СПИСОК ЛИТЕРАТУРЫ:}

1. Басов В.М. Экология мух рода Urophora (Diptera, Tephritidae) в условиях Среднего Поволжья и Предуралья: монография. Елец: ЕГУ им. И.А. Бунина, 2006. 185 с.

2. Басов В.М., Толстогузова И.А. Мухи-пестрокрылки - специализированные фитофаги сорных васильков на пастбищах // Проблемы экологии в сельском хозяйстве. Пенза, 1993. Ч. 1. С. 61-62.

3. Басов В.М., Сапаев Е.А. К вопросу об эволюции пищевой специализации насекомых в связи с деятельностью человека // Известия Харьковского энтомологического общества. Харьков, 1996. Т. IV. Вып. 1-2. С. 5-13.

4. Басов В.М. Пестрокрылки (Diptera, Tephritidae) Среднего Поволжья и Предуралья // Вестн. Удм. унта. 1999. № 5. С. 33-45.

5. Басов В.М. Закономерности развития экологофаунистических комплексов (на примере мух-пест- рокрылок Среднего Поволжья и Предуралья): дис. ... д-ра биол. наук. Ижевск, 2001. 393 с.

6. Басов В.М., Басова Л.В. Консорционные связи васильков (Asteraceae, Centaurea) и их специализированных фитофагов мух-пестрокрылок (Diptera, Tephritidae) в Волжско-Камском крае // Вестник Удмуртского ун-та. 2000. № 5. С. 86-95.

7. Корнеев В.А. Новый вид мух-пестрокрылок рода Terellia (Diptera, Tephritidae) из Молдавии // Вестник зоологии. 1990. № 5. С. 67-69.

8. Воловник С.В. Жуки-долгоносики рода Larinus Dej. в фауне Запорожской области Украины (Coleoptera, Curculionoidea) // Биологический вестник Мелитопольского педагогического ун-та им. Богдана Хмельницкого. 2011. Вып. 1. С. 15-21.

9. Определитель растений Среднего Поволжья / В.В. Благовещенский, Ю.А. Стариков, Н.С. Раков, В.В. Старикова, В.С. Шустов. Л.: Наука, 1984. 392 с.

10. Eber S., Sturm P., Brandl R. Genetic and morphological variation among Biotypes of Tephritis bardanae // Biochemical Systematics and Ecology. 1991. Vol. 19. № 7. P. 549-557.

11. Басов B.M. Мухи-пестрокрылки (Diptera, Tephritidae) национального парка «Нижняя Кама»: биотопическое распространение, кормовые растения // Растительный и животный мир национального парка «Нижняя Кама»: сб. науч. тр. / под науч. ред. В.М. Басова. Ижевск, УдГУ, 1997. С. 85-113.

\title{
THE STUDY OF BURDOCK BLOSSOMS (ASTERACEAE: ARCTIUM) ENTOMOFAUNA IN THE YELABUGA DISTRICT OF THE REPUBLIC OF TATARSTAN
}

\author{
Leontyeva Irina Aleksandrovna, senior lecturer of Biology and Chemistry Department \\ Elabuga Institute (branch) of Kazan (Volga Region) Federal University \\ (Elabuga, Republic of Tatarstan, Russian Federation)
}

\begin{abstract}
The paper deals with the study of burdock blossoms (Asteraceae: Arctium) in the Yelabuga District of the Republic of Tatarstan where they are one of the most common species among the Compositae plants. They are mostly ruderal weeds, growing usually in waste places (abandoned orchards, wastelands, ravines, roadsides, river banks, dumps, walls of houses and fences, etc.). Some representatives of this genus are also found in the floodplain forests, sparse deciduous forests, clearings, forest edges.

The paper presents some results of study of species composition and population structure of phytophagous insects, developing in inflorescences of four species of burdock (Arctium tomentozum, Arctium minus, Arctium lappa, Arctium nemorosum) on the territory of Yelabuga District of the Republic of Tatarstan. Seven experimental sites were examined, their total area is 1,0 hectares. The basic research was conducted during the spring-summer period in 2015-2017 at the time of active flowering plants. There were three kinds of flies-petrotrak (Diptera: Tephritidae), one kind of flies-Midge (in Russian spp.), one kind of beetle-weevil (Curculionidae) and one species of moth (Gelechiidae).

Keywords: insects-phytophages; diversity; inflorescence; forage plant; Arctium tomentozum; Arctium minus; Arctium lappa; Arctium nemorosum; food specialization; fitofage; Diptera; Coleoptera; Lepidoptera; Yelabuga city; Yelabuga District; Republic of Tatarstan.
\end{abstract}

УДК 502.504

Статья поступила в редакцию 01.10.2017

\section{ЭКОЛОГИЧЕСКОЕ СОСТОЯНИЕ МАЛЫХ РЕК ИК И СЮНЬ ШАРАНСКОГО РАЙОНА РЕСПУБЛИКИ БАШКОРТОСТАН}

(C) 2017

Нафикова Эльвина Ришатовна, магистрант кафедры биологии и экологии

Исламова Айсылу Айратовна, кандидат биологических наук, доцент кафедры биологии и экологии Бирский филиал Башкирского государственного университета (2. Бирск, Республика Башкортостан, Российская Федеращия)

Аннотация. В настоящее время очень заметно сказывается отрицательное воздействие человека на водные экосистемы. Это в конечном счете отразилось в изменении гидрологического режима рек и озер. Резко 